\title{
STUDY OF THE WETTING OF COKE BY DIFFERENT PITCHES
}

\author{
Ying Lu$^{1}$, Duygu Kocaefe ${ }^{1}$, Yasar Kocaefe ${ }^{1}$, Dipankar Bhattacharyay ${ }^{1}$, Xian-Ai Huang ${ }^{1}$, \\ Brigitte Morais ${ }^{2}$ \\ ${ }^{1}$ UQAC/AAI Research Chair on Carbon and REGAL Aluminum Research Center \\ University of Quebec at Chicoutimi 555 Boulevard de l'Université, Chicoutimi, QC, Canada G7H 2B1 \\ ${ }^{2}$ Aluminerie Alouette Inc., 400, Chemin de la Pointe-Noire, Sept-Îles, Québec, Canada G4R 5M9
}

Keywords: Wetting, carbon anodes, calcined petroleum coke, coal tar pitch

\begin{abstract}
Prebaked anodes are made of dry aggregates (coke, recycled butts and rejected green/baked anodes) and the binder pitch. During the mixing process, the wettability of coke by pitch influences the anode paste behavior. Coke particles $(+100 \mu \mathrm{m}$, $-125 \mu \mathrm{m})$ were prepared from the same source using two different procedures, and the wettability of cokes by five pitches with different properties was studied using a sessile-drop system at $170^{\circ} \mathrm{C}$. The contact angle results show that the wettability of coke by all pitches follows a similar trend for both cases, but the actual contact angles are different. The cokes and the pitch-coke interfaces were also investigated by the optical and scanningelectron microscopy (SEM) techniques. The image analysis results indicated that the coke particle size distribution depends on the coke preparation, which seems to influence its wettability.
\end{abstract}

\section{Introduction}

Prebaked carbon anodes consist of approximately $65 \%$ petroleum coke, 20\% recycled anodes and butts (about $85 \%$ dry aggregates), and $15 \%$ coal tar pitch (binder). They are used in the electrolytic alumina reduction process and thus are consumed during the electrolysis. Good binding between dry aggregates and pitch results in dense anodes and thereby greatly affects the final anode properties [1]. Wettability of coke by pitch is one of the important parameters which determines the quality of binding between coke and pitch [2].

Wetting can be physical due to intermolecular interactions known as adhesive and cohesive forces between solid (coke) and liquid (pitch) or can be chemical due to reactions at the solid-liquid interface [3, 4]. The interaction between coke and pitch depends on the properties of both pitch (i.e., chemical composition, surface tension, contact angle, viscosity, QI, mesophase content, etc.) and coke (i.e., particle size, structure, texture, chemical functional groups on the surface, porosity, etc.) [3-7]. For this reason, the modification of pitch and/or coke may alter the coke wettability by pitch.

The degree of wettability of a solid by a liquid can be described in terms of the angle formed between them when they are brought into a contact. The contact angle is a measure of the ability of a liquid to spread on the solid surface and penetrate through it if the solid is porous [2, 5, 6, 8-10]. It is reported in the literature that the sessile-drop technique, which monitors the change in contact angle with time under an inert gas atmosphere, can be used successfully for wettability studies [2, 5, 6, 8-10].

Different authors studied the structures of coke and/or pitch using SEM and optical microscopy techniques. They found that the variations in composition as well as physical properties of coke and pitch are accompanied by differences in their microstructures [5, 6, 8-12]. It was reported that coke particles were ground and sieved to have particles of $+100 \mu \mathrm{m} /-125 \mu \mathrm{m}$ size for the wetting tests [8]. However, there does not seem to be any published work on the effect of coke particle size distribution, caused by different coke preparation techniques, on the wettability of coke by pitch.

The objective of this study is to investigate the wetting of coke by different pitches. The work also involves the SEM characterization of the shape and size of coke particles. Furthermore, the pitch-coke 
interfaces were investigated using optical microscopy. The wettability tests were carried out using cokes which have particles in the same size range, but prepared using two different procedures. These procedures affected the particle size distribution. The wettability results for two cokes (from the same source, but prepared differently) with five pitches were compared. In addition, the results were correlated with the coke structures as well as the characteristics of pitch-coke interfaces obtained from the sessile-drops after the tests.

\section{Methodology}

\section{Materials used}

Five coal-tar pitches with different properties and one petroleum coke were used in this study. Table 1 summarizes the properties of the pitches as well as the coke. The calcined coke particles were sieved with $100 \mu \mathrm{m}$ and $125 \mu \mathrm{m}$ sieves. Two different preparation procedures were used as follows: 1) the coke particles were crushed and then sieved to get particles in the desired size range (marked as the crushed sample), 2) fine particles from the coke were sieved also with $100 \mu \mathrm{m}$ and $125 \mu \mathrm{m}$ sieves (marked as the original sample). Both series of samples were sieved for 2 minutes with the $125 \mu \mathrm{m}$ sieve to remove the larger particles and for 4 minutes with the $100 \mu \mathrm{m}$ sieve to remove the smaller particles.

\section{Sessile-drop system}

The wettability of coke by pitch was determined using a sessile-drop system at $170^{\circ} \mathrm{C}$, which is a typical mixing temperature used in industry. The sessile-drop system consists of a tube furnace, a pitch injection system, a graphite sample crucible, a digital video camera, and a vacuum pump (see Figure 1). The coke sample is placed in the graphite sample crucible and compacted in order to have a smooth coke bed surface. The injection chamber holds the solid pitch sample. This chamber has a small hole which is placed just above the coke substrate during the experiment. The air in the system is first purged with nitrogen, and then the experiments were conducted under nitrogen atmosphere. In order to decrease the oxygen and humidity content of nitrogen, the gas is passed through a number of traps before it enters the system. There are two entry lines for nitrogen. The main line is directly connected to the furnace tube for maintaining the inert atmosphere inside the tube. The other line that connects the injection chamber to the inert gas supply carries the nitrogen gas necessary for slightly pressurizing this chamber in order to force the molten pitch droplet out onto the surface of the coke substrate. A video of the drop is captured, and the images are saved in a computer. To measure the contact angle, the FTA 32 software is used.

Table 1: Properties of the coal tar pitches and the calcined petroleum coke

\begin{tabular}{|c|c|c|c|c|c|c|c|c|c|}
\hline \multirow{2}{*}{$\begin{array}{c}\text { Pitch } \\
\text { type }\end{array}$} & \multicolumn{4}{|c|}{$\begin{array}{c}\text { Atomic percentages } \\
\text { (wt\%) }\end{array}$} & S.P. & Q.I. & T.I. & $\begin{array}{c}\text { Beta } \\
\text { resin }\end{array}$ & C.V. \\
\cline { 2 - 8 } & $\mathrm{C}$ & $\mathrm{O}$ & $\mathrm{N}$ & $\mathrm{S}$ & & & & & \\
\hline Pitch-1 & 96.62 & 1.89 & 1.21 & 0.29 & 118.4 & 3.4 & 25.9 & 22.5 & 58.9 \\
\hline Pitch-2 & 96.93 & 1.74 & 1.07 & 0.25 & 119.6 & 6.9 & 29.1 & 22.2 & 59.1 \\
\hline Pitch-3 & 97.98 & 1.05 & 0.70 & 0.26 & 118.0 & 10.8 & 33.0 & 22.2 & 61.2 \\
\hline Pitch-4 & 98.01 & 1.25 & 0.53 & 0.21 & 121.5 & 7.5 & 29.6 & 22.1 & 59.9 \\
\hline Pitch-5 & 97.61 & 1.18 & 0.94 & 0.27 & 119.4 & 5.1 & 28.0 & 22.9 & 59.6 \\
\hline Coke & 95.89 & 2.53 & 0.60 & 0.98 & - & - & - & - & - \\
\hline
\end{tabular}

S.P.: Softening point $\left({ }^{\circ} \mathrm{C}\right)$,

Q.I. :Quinolone insoluble (wt \%),

T.I.: Toluene insoluble (wt \%),

Beta resin $=$ T.I. - Q.I (wt \%),

C.V.: Coking value (wt \%).

Each experiment was repeated twice, and the contact angle was taken as the average of these two results. After the experiments, the pitch-coke drops were cut vertically and studied with an optical microscope.

\section{Scanning electron microscope}

The cokes prepared with two different procedures were investigated using SEM. The original coke particles and the crushed samples were uniformly dispersed in a conductive tape on a specimen plate and vacuum-dried for one day at room temperature prior to SEM analysis. The SEM analysis was done 
using JEOL-JSM-6480LV with secondary electron scattering, a voltage of $20 \mathrm{kV}$ and a WD (Work Distance) of $19 \mathrm{~mm}$.

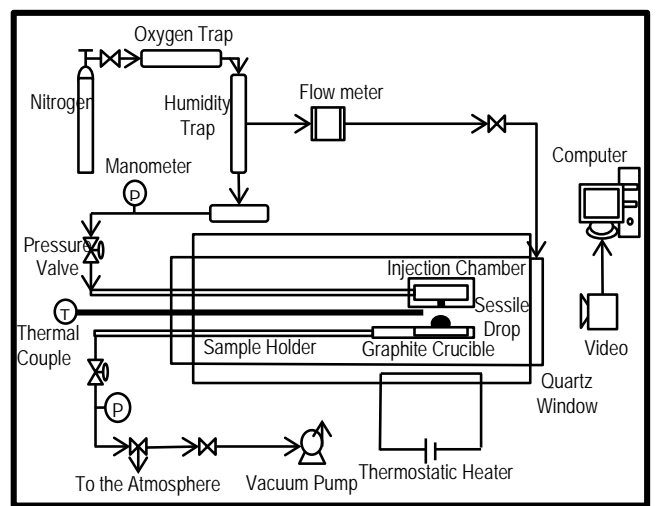

Figure 1 : Schematic diagram of sessile drop experimental set-up at UQAC

\section{$\underline{\text { Optical microscope }}$}

The optical microscope allows the examination of a larger surface area compared to that of the SEM technique. The solidified pitch-coke sessile-drops were sectioned vertically and polished to obtain smooth and flat surfaces containing the interface between coke particles and pitch. These surfaces were investigated using the Nikon Eclipse ME600P optical microscope and analyzed with the image analysis software Clemex Vision 4.0. This allows the visualization of pitch penetration through the coke particles as well as the interface of pitch and coke in the drop samples

\section{Results and discussion}

Wettability of coke by five different pitches: Effect of particle preparation

Figures 2 and 3 show the evolution of contact angles with time for five different pitches on two cokes (original and crushed), respectively. The contact angles for both pitch/coke systems decreased with the increasing time. The results also showed that the contact angles were different for the two cokes although their wettability by five pitches followed a similar trend; that is, Pitch-1 was the best-wetting and Pitch-5 was the leastwetting. The other pitches also followed the same order. The complete penetration time into the bed for the pitches (reaching zero contact angle) was significantly shorter for the original coke than the crushed coke. Some of the pitches did not penetrate completely into the crushed coke bed even after $1200 \mathrm{~s}$ as shown in Figure 3. However, the original coke absorbed all pitches within $300 \mathrm{~s}$ as shown in Figure 2.

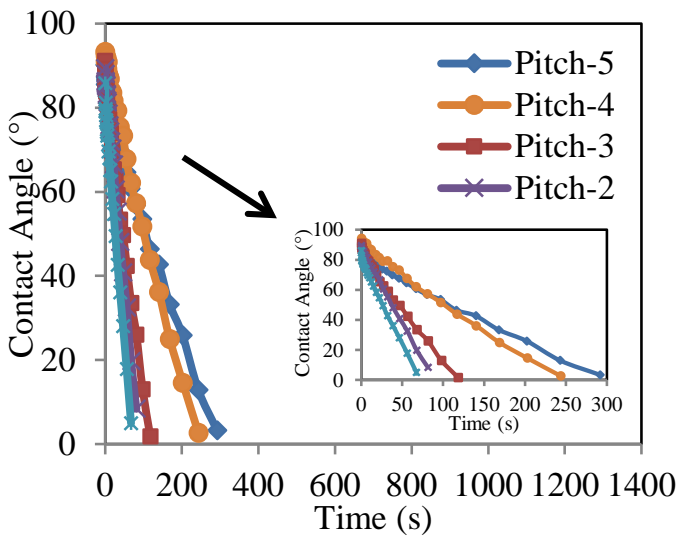

Figure 2 : Dynamic contact angles of five different pitches on original coke

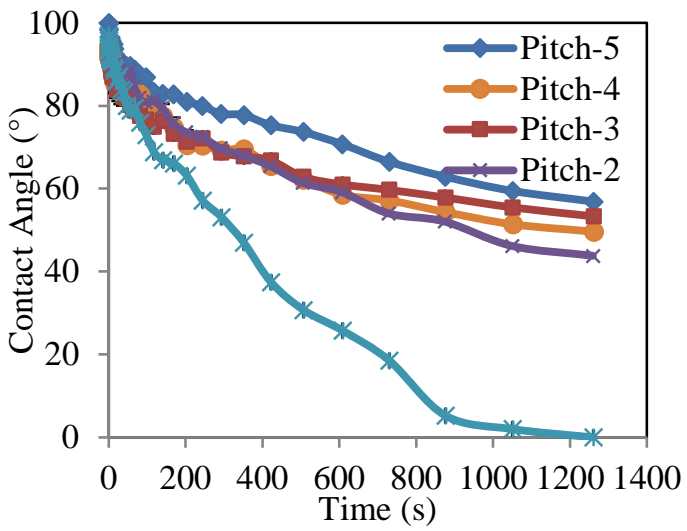

Figure 3 : Dynamic contact angles of five different pitches on crushed coke 
The contact angles measured at the initial time and at $60 \mathrm{~s}$ are shown in Figures 4 and 5, respectively, for all pitches as well as for the original and the crushed cokes. The initial time was set at $5 \mathrm{~s}$. The initial contact angles of all pitches on the original coke are slightly lower compared to those of the crushed coke (Figure 4). The initial contact angles for the same coke are similar with different pitches. However, the contact angles measured at 60 s for the original coke and the crushed coke are significantly different. The contact angles are much greater with the crushed coke showing that it is wetted less by all the pitches compared to the original coke.

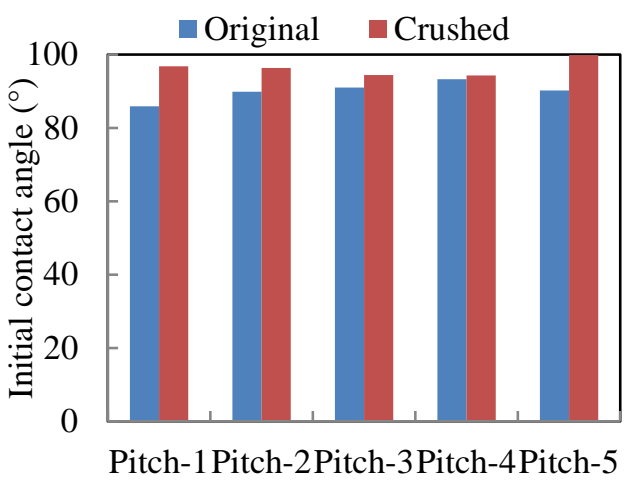

Figure 4 : Initial contact angles of five different pitches on coke

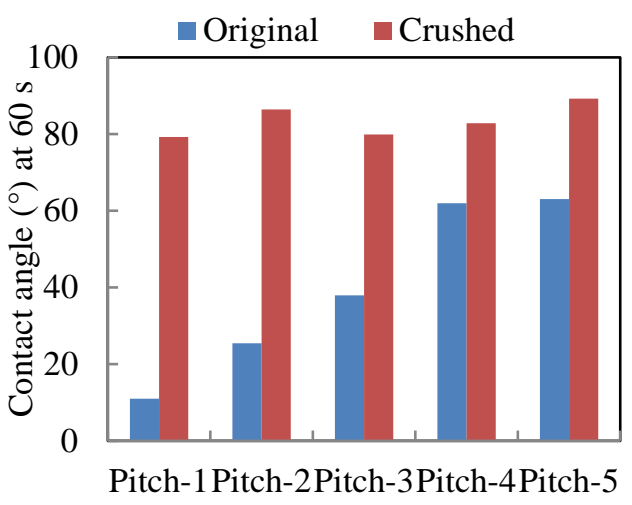

Figure 5 : Contact angle at 60 s of five different pitches on coke
In order to understand the difference in wettability of two coke beds, optical microscopy and image analysis of the cokes were carried out. The interfaces of pitch and coke in sessile-drops were also investigated using optical microscopy to understand the wetting mechanism.

\section{$\underline{\text { SEM analysis }}$}

SEM is a useful tool to visualize the shape and the size of coke particles. It was found that there is no notable difference in particle shape and surface texture between original and crushed coke particles within the same size range (see Figures 6 and 7). The SEM images of original coke in Figure 6 show that the particle sizes are in the range of $100 \mu \mathrm{m}$ and $125 \mu \mathrm{m}$. However, the crushed coke particles seem to have finer particles than those in the original coke particles even though they were both prepared using the same sieving procedure. Thus, crushing caused the generation of finer particles. The finer particles fill the space between bigger particles. The mixture of coarse and fine particles of the crushed coke results in a more compact coke bed than that of the original coke, and this reduces the pitch penetration into the coke bed.

\section{Optical microscopy analysis}

Figures 8 and 9 present the optical microscopy images of the pitch-coke interfaces in the sessiledrops for both cokes. Coke, pitch, and solid particles in the pitch can be easily seen on these images. Figure 8 shows that pitch penetrated into the original coke bed homogenously. Moreover, the solid particles of pitch are distributed homogenously in pitch around the coke particles. The coke particles are totally embedded by the pitch. The crushed coke bed however displays completely different characteristics. Different components of pitch seem to form layers during wetting as well as during the penetration of pitch (see Figure 9). Some of the solid particles of pitch were blocked by the finer crushed coke particles which prevent them entering into the coke bed. Consequently, a layer of solid particles was formed on the surface of the crushed coke bed. This layer 
acts as a filter and slows down the pitch penetration into the coke bed. This explains the lower wettability of crushed coke particles by the same pitches compared to the wettability of original coke particles. It can also explain the differences in contact angles observed at initial times and 60s. It takes some time for the filter-like layer to form. Until the formation of this layer, the angles are closer for both cokes. Later, the difference becomes more pronounced.

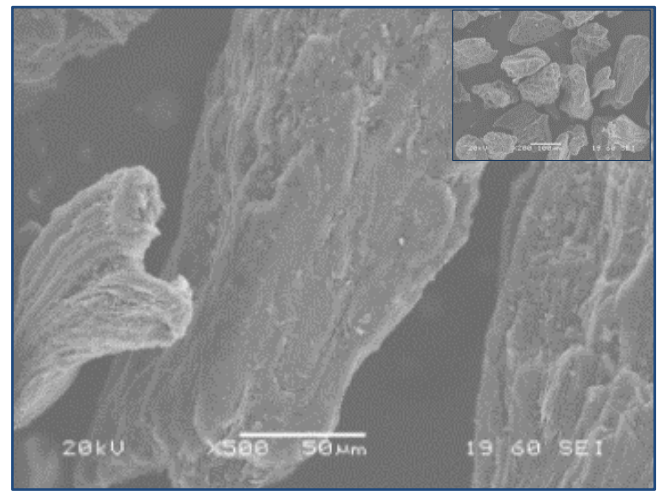

Figure 6 : SEM image of original coke

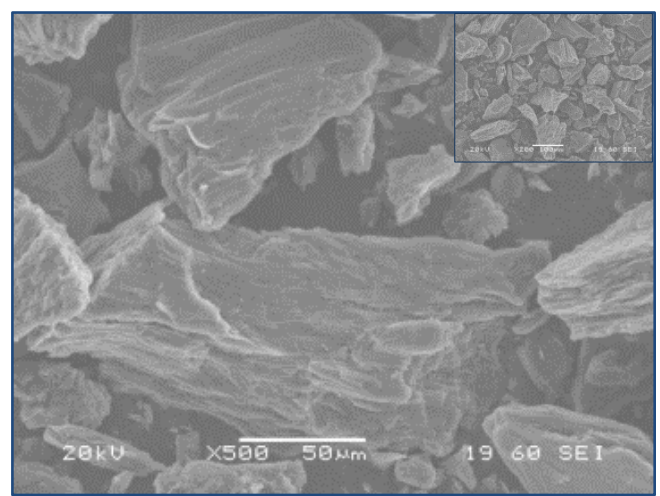

Figure 7 : SEM image of crushed coke

\section{Conclusions}

The dynamic contact angle results showed that the wettability of two coke samples by the same pitches is significantly different. These cokes were from the same source, but they were prepared differently. Therefore, the only difference between them was the amount of finer particles.

The SEM results indicated that the two cokes contained different amounts of finer particles. There are a lot of finer particles formed during crushing, and these filled the spaces between larger particles resulting in a better compaction of the coke bed. Thus, the pitch penetration was delayed. The presence of finer particles in coke seems to have a strong influence on the penetration of pitch into the coke.

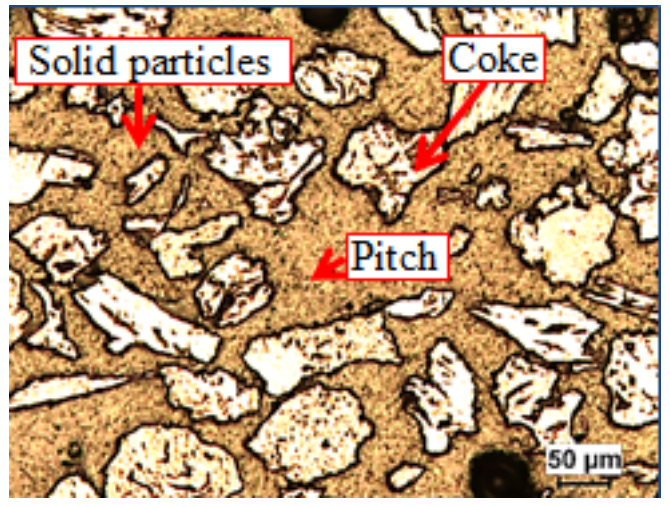

Figure 8 : Optical microscopy image of Pitch-3 with original coke

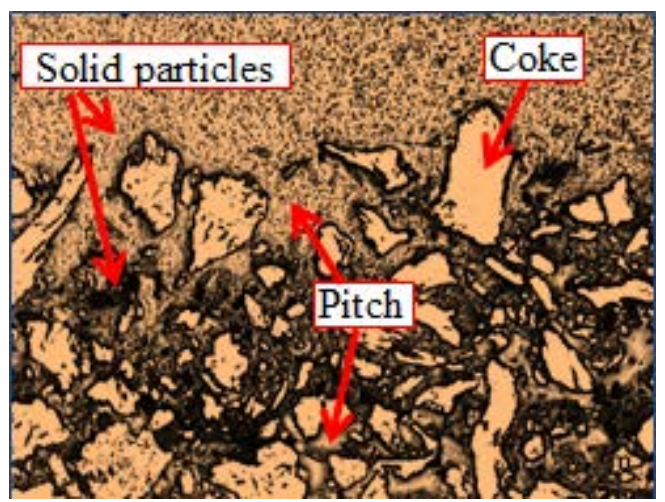

Figure 9 : Optical microscopy image of Pitch-3 with crushed coke 
The optical microscopy analysis showed that the solid particles in pitch are distributed differently at the pitch-coke interface depending on the coke particle size distribution. When the particle size distribution is more or less uniform, pitch solid particles are also distributed uniformly. If there is a wide coke particle size distribution, pitch solids can form a filter-like layer at the interface which slows down the pitch penetration into the coke bed. This, in turn, decreases the wettability. The complete mechanism of pitch/coke interactions is complex, and further work involving the chemical analysis of coke and pitch is needed to better understand this mechanism.

\section{Acknowledgements}

The technical and financial support of Aluminerie Alouette Inc. (AAI) as well as the financial support of the Natural Sciences and Engineering Research Council of Canada (NSERC), Développement économique Sept-Îles, the University of Québec at Chicoutimi (UQAC), and the Foundation of the University of Québec at Chicoutimi (FUQAC) are greatly appreciated. A part of the research presented in this paper was financed by the Fonds de recherche du Québec - Nature et technologies by the intermediary of the Aluminium Research Centre - REGAL.

\section{References}

1. Hulse, K.L., Anode manufacture : raw materials, formulation and processing parameters. 2000, Sierre [Suisse]: R \& D Carbon Ltd. xxxv, 416 p.

2. Couderc, P., P. Hyvernat, and J.L. Lemarchand, Correlations between ability of pitch to penetrate coke and the physical characteristics of prebaked anodes for the aluminium industry. Fuel, 1986. 65(2): p. 281-287.

3. V.I.Denisenko, et al., The wettign capacity of coal tar pitches. Tsvet.met.9, 1980(52-54).

4. Nefedov, P.Y., D.D. Zhuravleva, and A.N. Reshetko, Study of the process of wetting coals and carbonaceous materials by pitch. Solid Fuel Chemistry, 1978. 12(3): p. 18-24.
5. Sarkar, A., et al. Characterization of petroleum coke and butts used in anode manufacturing in aluminum industry. in Materials Science and Technology Conference and Exhibition 2013, MS and T 2013. 2014. Montreal, QC.

6. Rocha, V.G., et al., The effect of the substrate on pitch wetting behaviour. Fuel Processing Technology, 2010. 91(11): p. 1373-1377.

7. Dell, M.B. and R.W. Peterson, Wettability of petroleum cokes by pitch. Industrial and Engineering Chemistry Product Research and Development, 1970. 9(2): p. 190-194.

8. Rocha, V.G., et al., Pitch/coke wetting behaviour. Fuel, 2005. 84(12-13): p. 15501556.

9. Rocha, V.G., et al., An insight into pitch/substrate wetting behaviour. The effect of the substrate processing temperature on pitch wetting capacity. Fuel, 2007. 86(7-8): p. 10461052.

10.Sarkar, A., et al., Coke-pitch interactions during anode preparation. Fuel, 2014. 117(PART A): p. 598-607.

11.Hays, D., J.W. Patrick, and A. Walker, SEM characterization of cokes and carbons. Fuel, 1983. 62(9): p. 1079-1083.

12.Hays, D., J.W. Patrick, and A. Walker, SEM study of binder coke in electrode carbon. Fuel, 1983. 62(8): p. 946-952. 